\title{
7 \\ Mary Jane Fort, costume designer
}

Mary Jane Fort has more than two decades of experience as a costume designer on feature films such as Mean Girls (2004) and television shows such as Grounded for Life (2001-5). In this conversation, Fort explains the little-known aspects of the costume designer's job as well as creative collaboration, emotional labor, and gender dynamics on set.

Tell us about your job. What does a costume designer do?

A costume designer is a visual storyteller. We are at our best when we help the actor visualize the character and enable the actor to become his or her character. It's not about clothes or fashion. It's about contributing to a larger vision: Who are these characters and what is this story? My job is to capture that larger essence by breaking the story down into smaller components. How will all these parts work together to create the whole? I approach my job like a painter approaches a painting or a decorator approaches a room in a home. Each element you create helps deliver something bigger and more cohesive.

When do you join a project?

I come on pretty early in the preproduction process. I'll join the project after the director, director of photography, and production designers. They are my key collaborators. I work with them for quite some time to help design the overall look of the film or television show. 


\section{And when is the cast involved?}

Casting is often done at the eleventh hour, especially in television. It adds another element to my job. I can work with the production designer to coordinate a character's wardrobe for a particular space. He or she will tell me that the building's facade will have a green door, and I'll coordinate the colors to ensure that the characters stand out appropriately. Buildings don't talk back, but I'll have to adjust and negotiate my plans when the cast joins the project because oftentimes the talent won't feel comfortable in a particular color or outfit. They'll say, "I'm not going to do that." It adds an element of psychological or emotional labor to my work. I'll have to try to figure out how to make the actors more comfortable so they can do the job they were hired to do. I have to reassure them. I have to figure out how to translate our original plans in a way that makes sense to the actors and helps build their confidence instead of diminishing it. I have to understand how the actors want to approach the role and respect their creative process by incorporating their ideas into the overall vision. I think of it as layering as I bring all the ideas together.

\section{Can you talk more about the emotional labor?}

After I've had conversations with the director and the production designer, I'll meet the actors and talk. "How do you see this person? And who do you think he or she is?" Usually these people are all on the same page, and we'll talk about colors and shapes. I'll ask, "Is there anything that you hate or like?" After that we start the fittings. They'll come to a first fitting, and you start looking at things, and then you end up essentially finding the character. That may not happen during the first fitting, but often I'll say, "This is not quite right, but maybe something like this," or they'll say, "This doesn't make me feel right," or, "This kind of shoe, that does it!" And then I start editing out what didn't work. Most of the time the actor and I won't show anybody any options until we have it narrowed down to what we want. Then we'll show the director to get his or her input.

It's a process that sometimes runs more smoothly than other times. Through this process, we discover the character, and then I start breaking that out into the different changes we'll need to make according to the script. I also have to think about the environment. I'll join the production designer and set decorator to start looking at what I've done and what they've done. The DP [director of photography] then looks at all of it, and we'll see how it all works together. We have to talk about all the little things. "Does this work? Is that lamp's texture going to conflict with this shirt?" There are so many details. 
So it's a very creative collaboration, but also an intimate one. Actors are very vulnerable with you.

Absolutely. I see them without makeup. I see them without clothes.

How do you negotiate their insecurities and vulnerabilities?

If the actor doesn't feel comfortable with me, then I'm not doing my job. I've done something wrong somewhere in the process. Actors aren't fragile creatures. Some are, but most of them are there to do the job. They have no problem taking their clothes off in front me. [Laughs] There's always a dressing room, but no one uses it.

We're all invested in breathing life into this character. It's my job to protect the actors from being made to feel more vulnerable or less confident in their abilities, which can happen if I put them into costumes that accentuate insecurities. The actors may look perfectly fine to me, but I don't know what's going on inside their heads. If they don't feel like they look good, then that's going to get in the way of their best performance. Of course there are times when the actors need to look schlumpy or need to be in an ill-fitting suit. They understand that. But it doesn't do anyone any good to send them to the set in something that isn't working for them. I'll say to the director, "She's not feeling comfortable in the dress we chose. Can we try another one?" No director is going to say, "No! Let's make our star miserable!"

It's about how you communicate with the production team and the talent. If you disagree, then it's about working through that process. Perhaps you compromise and agree to see how the costume design looks on camera first. "Are you sure this is comfortable? Let's try it with this jacket before changing our minds, or maybe we should tighten it up here." Sometimes their initial instincts were correct. Sometimes they'll agree with me. Whatever the case, I want to make sure they are 100 percent confident in our choices before they go in front of the camera.

\section{When do you take on assistants for a film?}

I like to have them on day one, but it all depends on what the budget allows. For a midrange movie, you'll have about eight to ten weeks of prep time. I'll be there for two weeks to meet with my collaborators and gather ideas. Then I'll bring on a wardrobe supervisor who is the real brains of the department. That person manages every single logistical element in the costume department: budgets, supplies, materials, script breakdowns. I can't do my job without a good wardrobe supervisor. 
Your most recent project was Project Almanac (2015), a sci-fi feature film. What does a film like that require from the costume department? Help us get our heads around budgets, characters, costume changes, et cetera.

Project Almanac was a midrange feature with a budget of approximately $\$ 12$ to $\$ 15$ million. I think the first six or seven characters on the call sheet had about fifteen to twenty changes each. Any adjustment qualifies as a change. A character may wear one thing in the morning but then add a jacket for dinner or change into a bathrobe at night to brush her teeth. It was a relatively easy project to handle because we were dealing with discrete chunks of time as the characters traveled through time-a few weeks here in this world and then a few weeks there in that world. Compare that to something like Mean Girls where we had to accommodate an entire academic year. So Project Almanac was relatively simple, while Mean Girls required many more changes. The latter was so very, very, very detail oriented. I had so many subtleties to track. You have to have an excellent group of people around you.

All of these details and changes are ultimately my responsibility. I may not do the breakdowns, but if something is done wrong, I'm the one who has to say, "Sorry, we did it wrong." Surrounding myself with great people gives me the freedom to be creative. I think one of the things that I love so much about the medium of film is that everyone truly depends on everyone else. If one element is missing or goes askew, you can't do it. Everyone has to work together. It's what makes it so much fun for me.

At this point in your career, do you have a team that you work with consistently?

I have my team, but they aren't obligated to work solely with me. Somebody will inevitably have another commitment when I'm working on a project. So you have a roster of people you know and trust. Sometimes your entire dream team is available. Sometimes you have to bring on somebody new. It can be a lot of fun, or it can be a nightmare. You never know!

Do you do the hiring?

Yes, indeed. I hire the wardrobe supervisor. I come with people, and generally he or she has people as well. Together, we decide who is right for a particular project and we budget who and what we need. That is our core group, and then for different days that are big or particular parts of the script that are challenging, we have extra "man days." Although it could happen, I've never had production oppose someone I wished to hire. 
How big is the department on a midrange feature film?

I'll have a core team of eight to ten people, with additional help occasionally coming in throughout production.

How did you become a costume designer?

It happened by accident. I studied as a painter. I have a bachelor's degree in fine arts. I'm from a small town in Tennessee, and I wanted to move to New York and work in fashion design on Seventh Avenue. I didn't know how. I didn't study fashion design, but it's just what I wanted to do. So in the late 1980s, I moved to New York. I was designing T-shirts for Swatch, and then the head designer left because of some conflict with the company. Production ceased, but our contracts wouldn't let us work for anyone else. My friend was an assistant to Jonathan Demme at the time. She asked, "Can you work for free?" He was producing a short film that needed a costume PA [production assistant]. I did that for no fee and absolutely loved it. So I thought, "How do people do this?" No one could tell me! Someone said, "Read the trades." Remember, this was before Google. Jobs were advertised in the trade magazines. I ended up responding to an ad in the Hollywood Reporter for the Whit Stillman film Metropolitan (1990). I got it. I had no idea what I was doing, but I was doing it for $\$ 200$ a week. I used my own clothes, my own resources. I kept everything in my apartment in New York. I took it to work each day in a cab that I paid for. It was Stillman's debut film and it ended up doing really well, so an agent called me to ask if I wanted representation. Again, I had no clue what he meant. But he explained it, and I was like, "Sure!"

It's a funny way to get into the business. I never came up through the ranks. I was never an assistant. I've always been the department head, which means I've made lots of mistakes. I've lived. I've learned.

When did you start doing television? Why?

I started doing television about ten years ago. Television allows you to have more of a plan. You know when you'll have holiday time. You know when you'll be at home. It's less of a gypsy lifestyle, and it was at a time in my life when I wanted that. At least that's how television production was ten years ago when we were making television in Los Angeles. Now we're making television in Atlanta, Dallas, or Philadelphia, and television is as much of a gypsy lifestyle as film.

When did that start to happen?

I didn't start leaving the area for long periods of time until five years ago. I've worked in Philadelphia, Atlanta, Dallas, New York, Nashville. And Canada, of course. 


\section{How does that feel?}

It can be fun. You get to see different places, though right now being in Atlanta is like being in Los Angeles. You almost know more people in Atlanta than you do at home because so many people are moving there to work. It's also challenging to work in these different areas. I honestly don't know how it saves the production any money. You can never find local crew who are skilled enough to do the work you need. You end up bringing people with you, but it's still a logistical nightmare.

You start with one assistant and your wardrobe supervisor-that's who you can bring on from the beginning - but then you have to staff your department with local hires. We are obligated to try. You talk to the local union, and its staff reassures you that it has all these great people who are eager to work. The area may have eager people, but those people either lack the proper training or they just want to work "in the movies" without actually doing the work that's required. I've had people steal money or walk away with clothes. It just adds so many hoops to jump through. I don't want to disparage local crews - they simply haven't been doing it long enough, and there aren't enough of them. It'll change in time.

\section{Or maybe not.}

I don't know. I did a TV series in Philadelphia. Because of the incentive program, we were supposed to hire local crew and purchase our materials locally. No one wanted to take the job! No one wanted to make a long-term commitment! We interviewed people, and they would say, "I can work for a month then I'm going to make a music video. But I can come back." It just doesn't work that way. Do you want a job for this amount of time or not? We already had a small labor pool, and then we couldn't find anyone to hire. I ended up bringing five people with me. I had the same experience when it came to purchasing. We ended up doing most of our shopping in New York. Philadelphia stores didn't stock what we needed. If there's a sweater available in September, it'll still be there in January. We needed more variety for this particular show. It took so much labor to prove our point, and finally, the producer just said, "Okay. Bring your people and purchase in New York."

\section{Do you ever just throw up your hands and scream, "Not this again!"?}

I don't, because I know it will all work out. I've never had somebody say to me, "Well, that's just too bad. I know these people are unqualified, but you have to deal with it." No one wants to ruin the project. Everyone has a boss. A line producer doesn't want to look like she mucked it all up any more than I do! A smart line producer will let me hire the people I need to ensure the best possible outcome. If 
I can't do something because I don't have the staff, then the line producer will look bad, too. We all want to do our best.

\section{Where is the disconnect?}

It's with the people who sit in buildings somewhere far away from the set. We laugh about it all the time. You never meet these people. You never see them. They're like little ghosts who develop universal formulas that may look logical on paper but not in practice. For example, during pilot season, there's a process called "the pattern." It basically establishes the prep times for each department. I'll get three weeks for prep. It doesn't matter if it's a pilot for Lewis and Clark or Three Men and a Table. I get the same prep time. It's laughable. How can I prep this historical period piece in three weeks? They'll spend more money to make it fit into the formula than to develop a new formula. They won't give me a month prep time. Instead they'll double up on crew. Everyone works seven days a week, fourteen hours a day, for three weeks.

\section{Doesn't that take a toll?}

Of course! But you know it's going to happen. You know it's going to be crazy. You know it'll get done. It's only three weeks.

\section{How are you compensated? Hourly?}

Not me. I'm paid by the week, and I work a five-day week. For days six and seven, I get time and a half and double time. But for my crew, it's hourly. Again, it's time and a half and double time when you get into long hours. I think a wardrobe supervisor might make more than I do. They work hard.

Ultimately everything gets done, but it does open the door to exploitation, yes?

It does. I care about the art of it. I care about the craft. I want to do a good job. So I continually prove I'll get it done under the conditions they create for me, no matter how many hours it takes.

You have an excellent temperament for this job. Are most costume designers like you?

I have heard that sometimes people can be so attached to their vision that they can't let go of it. But again, that's not my philosophy. It's not about me. It's about what I can bring to the table. 
If the director sees something differently, I can argue: "I don't agree, and I think we should do this, this, and this." But if somebody says, "Absolutely not. I want it this way," I'm not going to throw a tantrum, yelling, "I worked so hard on this. I can't believe you don't want to use it!" I have other things going on. I don't want to say it's not important, because it's all important, but it's not worth it. It distracts you from the bigger picture. I'm already juggling so many details that I'm not going to stomp around when one of them doesn't go my way. Ultimately, it's not my movie.

It's almost a necessary philosophy when so much of your labor is invisible. Yet you have an artistic vision that contributes in meaningful ways.

Yes, absolutely! My job is to help visually tell the story through what the characters wear. If I do my job well, I don't draw attention to that process. It would be distracting and contrary to my objective. Yet I help guide what you see in particular scenes. I help create meaning. Who are these characters? What are they thinking or feeling? How are they evolving? It's an integral component to the overall vision of the film. Creative collaboration is a challenge, but I find it a rewarding one. I love it. I can't imagine doing anything else.

Do you work a lot? Do you have downtime between projects?

It all depends. I had years of overlap when I was doing two things at once, and then I sort of developed a life. Things happen and you need to take a little step back, and then you'll get back onto the treadmill again. I can't do a million things at once like I used to be able to do; I don't enjoy that anymore.

I used to do a movie and a TV show at the same time, but then the people around you suffer and your quality of life suffers, and the job takes a toll. I'm good at taking time off, but I'm also fine with working a year or so straight and then taking a break and jumping into it again. I know some people who never take a minute off.

You're not anxious about the next job?

I think everyone is to a degree. I probably should be more anxious!

Have you had the same agent for your whole career, or have you changed?

I was with Gersh for a very long time, and I changed to Innovative two years ago. 
And why was that?

I loved the Gersh agency, and I love the agents there, but they don't have a strong focus on television. It's kind of crazy to me because everybody's doing television now. And so I made the decision to change, but I do miss them.

Does the agency play an important role for costume designers?

You have to have an agent.

Really?

Yes, unfortunately. [Laughter] Everyone has a love-hate relationship with his or her agent. You like them as people, but after a point, you're doing so much repeat business with employers you already know that you forget whether you met them by chance or whether your agency made the connection. Over time you meet people, and after a certain point you'll work with them over and over again. You have your people who call you, and then every so often your agent will get you something new.

How does compensation work with your agent? Does the agent only get a fee when he or she brings you something?

No. They negotiate your deals and most of them take 10 percent whether the job came through them or through a personal connection. But, in their defense, negotiating often becomes so much more complicated than it sounds. The same day I signed with Innovative somebody called and asked me to do Project Almanac, and the agent helped me protect my credit, travel, accommodations, and all those things. They're sort of a necessary evil.

What are the gender dynamics in costume departments? Are there more women than men?

There are many more women in the department than men. I have worked with one or two great guys, but the core group I've kept together over the past ten years is women. It wasn't intentional, but we ended up becoming close and forming friendships.

Do you think that's because you spend a lot of time together?

It's a miserable experience if you can't work together. You need to get along to do this job well. One sour lemon can ruin the entire experience. It's horrible. 
How do the gender dynamics affect the department's relationships with other crew on the set?

It certainly factors into the way other people interact with us, and it bugs me. I can't stand it when I hear someone call for "the vanities." Really? No, that's not what we are. I also take offense when I hear someone call us "Wardrobe." Again, that's not what we are. Of course, the actor comes to the set followed by a makeup artist, a set costumer, maybe a hair stylist. So, maybe it looks like that's all we do, but I've just spent the past hour telling you everything we do! There's so much more that goes into this profession. I feel like people can be demeaning to the costume department, and I take great umbrage to that.

\section{They call you the vanities?}

An AD will say, "Where are the vanities? We're getting ready to shoot." So the makeup artist will come in and powder a nose, and the set costumer will tweak the collars. It's just rude. They have names. They're professionals. You can say, "Where's Sarah, and where's Elizabeth? We're getting ready to shoot." It's not just demeaning; it's also dismissive of our craft.

\section{And this is happening in front of a crew that's 80 percent white men.}

Yes. What they're really asking is, "Where are the girls?" Don't get me wrong. There are some fantastic male costume designers, makeup artists, and wardrobe supervisors. But the department is gendered as female and feminine. That's how it's seen.

Do you think there's a need for change as far as gender dynamics on the sets?

I hate to sound like I'm complaining. I don't want to whine about it. I want everyone to have the job he or she wants. I've never wished to be a DP, and I don't know a DP who has ever wished to be a costume designer. And I think the film industry is open to that: do what you want to do, and no one will stop you if you're good at it. The only place I know where the male-female ratio is off is with line producers. While the industry has some excellent female line producers, there are not as many, and they make less than their male colleagues. And I'm talking about line producers who work on major tent-pole movies. Only like a handful of female line producers work on that type of film. That's where you see the inequality, because it's a boys' club. Women aren't perceived as authoritative enough or aggressive enough to handle the responsibilities and to wrangle the crew and budgets and whatnot. 
But it's not just a matter of numbers. It raises questions about value and about whether the set is an inviting space for certain people.

I always feel welcomed. I've never felt unwelcomed.

Interesting. We've been told that sometimes stand-ins are treated horribly by crew. [Stand-ins are hired to take the place of actors while cameras, lights, and rigging are set up for a shot. On some sets, women who perform these tasks are subjected to inappropriate comments and overtures from male crew members.]

Oh, absolutely! It all depends on whom you're working with. Some projects have completely horrible, sleazy people, and other sets have some of the most wonderful people in the world. Every set has a different dynamic and vibe, but it's a trickledown from the top, because that vibe comes from the people who put together the crew. So if you have a great director and a great line producer and producer, for the most part you're going to have a crew stocked with admirable, respectful people who are good at their jobs. But if you have a director and producers who do not have very high standards for themselves and say whatever they want, then they generally don't mind when somebody else behaves inappropriately, and that's when situations get very frustrating.

You knew immediately what we meant when we said "stand-ins."

Of course. I have witnessed some bad things. I have had some bad experiences. I've been lucky to work with wonderful people more often than sleazy people. But they're there.

One last question about gender dynamics, which is more of a structural question. Do you think the industry is particularly challenging for women because of the way work is organized? The long hours, the constant mobility - is that hard for someone who wants to have a career and a family? Women still face a different set of cultural expectations than men: they're supposed to shuttle the kids to soccer practice and manage the home. Does that make it hard for women who are working in production?

It's very hard. A lot of people make choices at certain times in their lives. Perhaps they decide they're not going to travel for work. Perhaps they try to figure out how to make work more accommodating. If their children are young, they can bring them to work for a certain amount of time, but then the children reach an age when they're in soccer, and they don't want to go to work with mom. Everyone makes different decisions. I've even known people who have left Los Angeles. They just weren't able to make it all fit together. So, yes, it is difficult. 
For me, my parents were older and not living near Los Angeles, and they had needs. My father died, my mother had surgery scheduled, and somebody had to be with her. I needed to be able to plan when I could do these things. Everyone has things like that, and you hopefully work with people who will try to cover for one another. I did have that support.

Say you need to leave on a Thursday and be gone until Monday morning. Hopefully your department will help you work it out. As far as the people who work for me, I try to be respectful of balancing their time commitments and needs. Let's say that on Thursdays someone has to drive carpool. All right, we'll figure it out, and she won't come in until nine o'clock. We try to all work together. Nobody else knows how we balance schedules or even that we do it. There was one woman who worked with me who put her child in a daycare near Fox, which was where we were working, but the daycare closed at six. She would run to get her, bring her back, and everyone would pitch in to help. We had this beautiful baby with us in the evenings.

But again, nobody is aware of any of those exceptions. I don't think you could do that if you were in the camera department, or if you were a grip. It depends on your job. It isn't that there aren't great women DPs, but there just isn't a support system.

Exactly. It isn't intentional, but it plays out structurally.

It takes individuals who are willing to make those exceptions. "You can go a little early if you need to pick up your kid from daycare."

And structurally, workplace expectations aren't the same in every department.

They aren't. Really, it's about the people you work with. That plays a huge part because it's long days and hard work. It's stressful and it's hectic. You need personalities you can work with, and you need generosity, kindness, and professionalism. It's a great set when everyone shares those values. 